University of Wollongong

Research Online

Faculty of Law, Humanities and the Arts Papers (Archive)

Faculty of Arts, Social Sciences \& Humanities

$1-1-2017$

Model United Nations and deep learning: theoretical and professional learning

Susan Engel

University of Wollongong

Josh Pallas

University of Wollongong

Sarah Lambert

University of Wollongong

Follow this and additional works at: https://ro.uow.edu.au/lhapapers

Part of the Arts and Humanities Commons, and the Law Commons

Research Online is the open access institutional repository for the University of Wollongong. For further information contact the UOW Library: research-pubs@uow.edu.au 


\title{
Model United Nations and deep learning: theoretical and professional learning
}

\begin{abstract}
This article demonstrates that the purposeful subject design, incorporating a Model United Nations (MUN), facilitated deep learning and professional skills attainment in the field of International Relations. Deep learning was promoted in subject design by linking learning objectives to Anderson and Krathwohl's (2001) four levels of knowledge or cognition: factual, conceptual, procedural, and metacognitive. Students demonstrated improvement in all four areas; however, this article focuses on outcomes in the conceptual and metacognitive realms as these were where students showed the most growth. In the conceptual realm, the subject aimed to increase students' capacity to apply international relations theories. Students tended to utilize the traditional theories of realism and liberalism; however, their explanations and applications of these theories showed deep learning. In the metacognitive realm, students were able to analyze their own negotiation styles and to explain how it influenced their approach to the Model UN, thus demonstrating strong professional skills development and metacognitive growth. Learning was enhanced by the use of open access online subject materials and online communications. The subject was designed and run in a context where simulations in teaching politics and international relations are not common.
\end{abstract}

\section{Keywords}

nations, deep, united, learning:, model, theoretical, professional, learning

\section{Disciplines}

Arts and Humanities | Law

\section{Publication Details}

Engel, S., Pallas, J. \& Lambert, S. (2017). Model United Nations and deep learning: theoretical and professional learning. Journal of Political Science Education, 13 (2), 171-184. 


\title{
Model United Nations and Deep Learning: Theoretical and Professional Learning
}

Susan Engel, Josh Pallas \& Sarah Lambert

This is a pre-publication version of Susan Engel, Josh Pallas \& Sarah Lambert (2017). 'Model United Nations and Deep Learning: Theoretical and Professional Learning,' Journal of Political Science Education, DOI: 10.1080/15512169.2016.1250644

\begin{abstract}
This paper demonstrates that the purposeful subject design incorporating a Model United Nations (MUN) facilitated deep learning and professional skills attainment in the field of International Relations. Deep learning was promoted in subject design by linking learning objectives to Anderson and Krathwohl's (2001) four levels of knowledge or cognition: factual, conceptual, procedural and metacognitive. Students demonstrated improvement in all four areas, however, this article focuses on outcomes in the conceptual and metacognitive realms as these were where students showed the most growth. In the conceptual realm, the subject aimed to increase students' capacity to apply international relations theories. Student tended to utilize the traditional theories of realism and liberalism, however, their explanations and applications of these theories showed deep learning. In the metacognitive realm, students were able to analyse their own negotiation styles and explain how it influenced their approach to the Model UN, thus demonstrating strong professional skills development and metacognitive growth. Learning was enhanced by the use of open access online subject materials and online communications. The subject was designed and run in a context where simulations in teaching politics and international relations are not common.
\end{abstract}

Keywords: Model United Nations, simulations, deep learning, international relations theories, professional development

\section{INTRODUCTION}

Model United Nations (MUN) is an experiential learning technique where participants discuss ideas and brainstorm solutions to global challenges as model diplomats. Australia has not been as quick to embrace simulations in the teaching of International Relations (IR) and MUNs as in other parts of the world. In a survey of politics and IR curricula at ten institutions in Australia, hardly any subjects mentioned simulations, though we have since learned of two new simulations. ${ }^{1}$ Elsewhere, the use of simulations in IR has grown and MUNs are "one of the most popular active learning techniques" (Crossley-Frolick 2010, 184). ${ }^{2}$ Asal (2005) found that there was a lack of literature on integrating them into curriculum. Since then, though, the literature has expanded and when we introduced a MUN as a core subject into a major in IR we were able to develop it through engagement with good literature on simulations in general and specifically in IR.

Our subject was constructed around the simulation, thus the preparation for the simulation and the complexity and depth of the simulation was high. ${ }^{3}$ The lectures and subject material were all online and the subject was available to on campus students as well as an open access cohort concurrently, which is known as an "open boundary" subject. We created a range of new material for the subject but also reused existing open access material, which allowed the students to hear from experts in the field. All the subject material is licensed creative commons, by attribution, share alike and thus is available for re-use (see: http://course.oeru.org/mun/about/about-the-course/, we welcome suggestions for additional material and improvements). 
These elements added interesting challenges to the subject, however the analysis in this paper focuses on students' learning in areas identified within teaching and learning literature as keys to deep learning. Biggs and Tang's (2011) influential work argued that active learning is the key to ensuring deep learning. Model UN's have been a key tool to facilitate this in IR (Asal 2005; Shaw 2010; Chasek 2005). Yet, as Haack $(2008,395)$ argued, "merely taking part in activities - 'doing politics' - may not be sufficient to achieve deep learning." Haack (2008) argued for systematic scaffolded learning on the UN throughout the undergraduate or graduate curriculum as well as for a MUN curriculum that see students abstracting from their experience to bigger questions about the UN and IR. We introduced the MUN as part of a new core set of subjects in a broad IR curriculum, rather than in UN studies as Haack focuses on, and actively designed the curriculum to promote deep learning. Biggs and Tang (2011, 28-9) argued that deep learning requires activating cognitive functions ranging from the high to low. Anderson and Krathwohl (2001) provided a more systematic approach to cognition, outlining four levels of knowledge involved in deep learning: factual knowledge: the key elements students must know to effectively solve problems in a particular field; conceptual knowledge: students' understanding of the web of relationships between ideas; procedural knowledge: knowing how to do things and metacognitive knowledge: students' awareness of their learning. They argued that to create deep learning, subjects need to ensure that all of the levels are in operation. Pettenger, West and Young $(2014,495-6)$ used this framework to evaluate the design of simulations and their approach informed our analysis, though their focus was on procedural knowledge. We integrated these levels of knowledge into the subject's learning objectives, as outlined in the following section. In analysing the qualitative data we gathered on the subject, we found that deep learning had occurred across all four levels of knowledge but that two levels of knowledge stood out in terms of students' progress. These were conceptual knowledge around IR theories and practices; and metacognitive knowledge around students' learning journey. This paper outlines our outcomes in these areas in depth and contrasts this to existing literature. To set the context, we first outline how the subject was constructed utilizing the key levels of knowledge approach and other academic literature on MUNs and describe the subject's context and how it was run.

\section{SubJect Design}

The subject is an upper level subject in an IR major. It is a core subject and part of a scaffolded program to help foster deep learning (Haack 2008; Hertel and Millis 2002). The majority of students are enrolled in the Bachelor of International Studies or doing a major in political science, in a Bachelor of Arts. The Australian context, and particularly our context at the University of Wollongong, is important because no student from the course had ever participated in a tertiary MUN conference and only two had participated in a MUN at high school. Indeed, given the limited engagement with MUNs across Australia, very few of the students had even heard of them.

The subject was run over a semester with 13 weeks of online lectures and 11 weeks of tutorials, four of which were devoted to the simulation. Preparatory modules focused on: global governance and the UN system, researching and writing country and briefing papers and international diplomacy and negotiations. At census date, there were 55 students in the subject and we only retained one active open access student - as it was the first time the subject was offered, the open access aspect of the subject was not extensively promoted. Students were divided into three tutorial classes, which ran for two hours face-to-face.

In designing the MUN, Crossley-Frolick's (2010) work provided a framework for identifying the key issues in developing a quality MUN. The relevant literature against each topic was also identified to ensure the project was informed by best practice research (see box 1). 


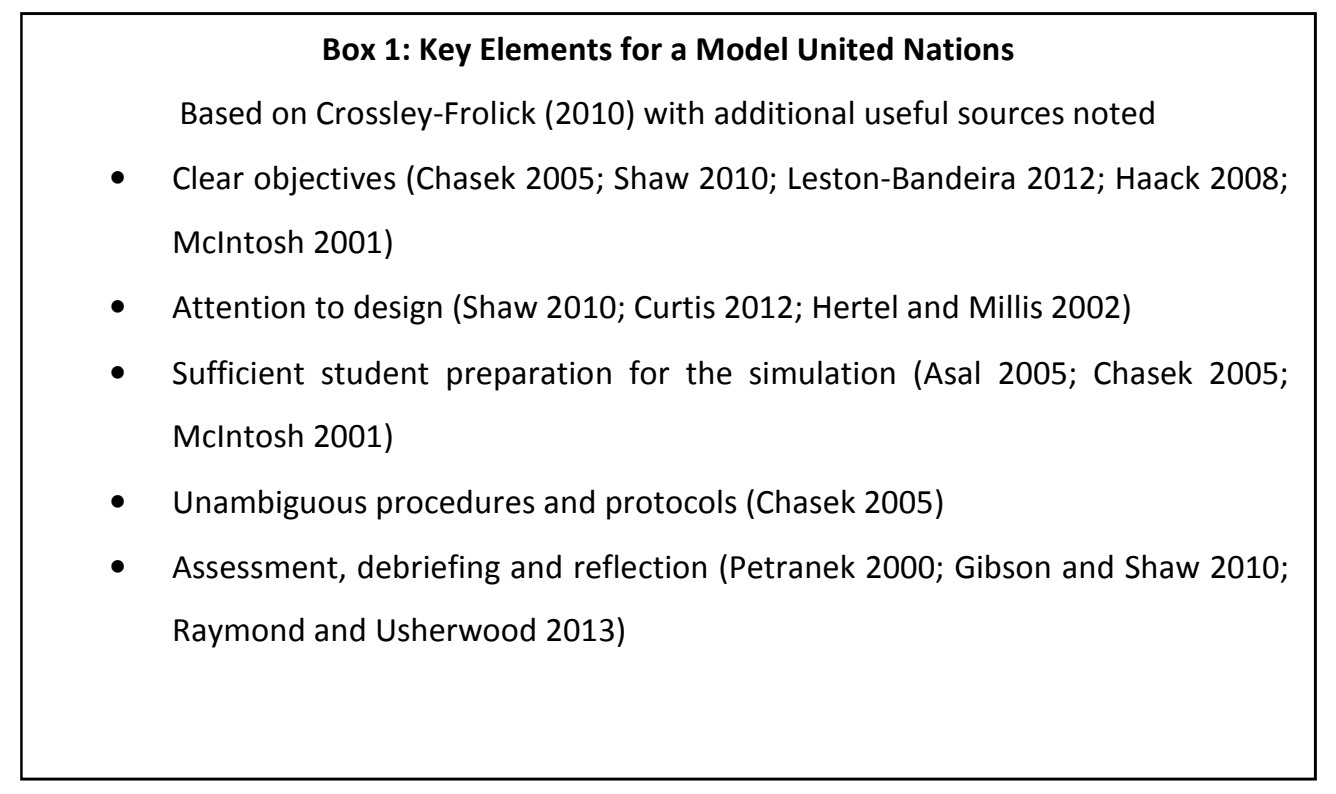

The subject's objectives and assessment were framed by the desire to introduce more substantive active learning into our overall program as well as to ensure development of core knowledge for the IR major using used Anderson and Krathwohl's (2001) approach to knowledge. The learning objectives directly relate to the four levels of knowledge, thus to advance factual knowledge, there was a criteria on knowledge of the role and functions of the United Nations system. Students' progress was assessed through a quiz on the UN system. Growth in conceptual knowledge centred on improving students' capacity to understand and apply IR theories, this was linked to assessment through the quiz and a written reflective journal. This asked students to link their experiences in the simulation to theoretical approaches to IR as well as their capacity to represent their chosen country and their negotiation style, that is to say about metacognitive reflections on professional skills development. In terms of procedural knowledge, students needed to the capacity to write policy papers (Trueb 2013), and these were submitted as an assessment. They also needed to use MUN rules and procedure and learn about negotiation skills. Their progress here was assessed over the four weeks of the simulation, with a weighting towards the final weeks to allow them to become familiar with the procedures and to encourage them to demonstrate their learning over the simulation. In the realm of metacognitive knowledge, as noted above, the reflective journal asked students to reflect upon personal and societal assumptions and be able to challenge these and to consider their strengths and weaknesses in key skills areas needed for global careers.

The design of the subject was linked to the objectives. Module 1 was three weeks and it introduced global governance and the UN system, framed by an engagement with theories of IR, thus it focused on the factual and conceptual knowledge levels. This was only a short module, designed to build on basic knowledge from first year IR studies. Modules 2 and 3 were focused on procedural knowledge, they were on respectively researching and writing a country and policy paper (three weeks) and on diplomacy and negotiation (two weeks). They were taught using examples from the UN system and the six committees of the General Assembly to reinforced and develop factual knowledge. The fourth module was the simulation (four weeks), which ended with a separate debriefing session (one week), thus debriefing was done both in class and individually by the students to underline its importance. The completed subject design reflects the complexity of designing a curriculum that effectively balances the factual, conceptual, procedural and metacognitive knowledge required for students to effectively engage in a university level MUN, even with the benefit of a range of good literature to guide it. At the same time, we tried to remember the maxim that too much coverage destroys understanding (Biggs and Tang 2011, 43).

In terms of student preparation, in addition to the extensive preparation built into the design of the subject, the tutorials followed the flipped classroom model with students engaged in active learning. For example, one 
tutorial had 30 minutes devoted to group research on the role of one of the six committees of the General Assembly. After each group reported back, there was an initial discussion about which of the committees they would be most interested in simulating. Thus activities were split between factual, conceptual and procedural knowledge. There were sessions on how to complete their country and position paper research; a MiniMUN on the death penalty to get students used to the formal style and the rules of procedure and protocols of the MUN; ${ }^{4}$ and the diplomacy and negotiation included a negotiation role play. The open access student was kept involved by tweeting from one of the tutorial groups and encouragement to use the online group workspace, though this only became truly active once the simulation started.

\section{Box 2: On Topic and Country Selection}

\section{Balancing Student Centred Learning and Guidance}

Guided by literature on the benefits of student centred learning and choice (Crossley-Frolick 2010) we started with maximum student choice on simulation topic and country. Students selected a country early for the MiniMUN and other active learning tasks. The self-selection aimed to increase their ownership, with the caveat that they could not select their home country so no student was unfairly advantaged. Where two or more students were interested in the same country, a compromise was reached, sometimes with suggestions from class instructors. Some students were encouraged to revise their country choice once the final topic for the simulation was decided so that relevant countries were represented.

There are a range of other methods for selection, ranging from lotteries to allocation while Chasek $(2005,5)$ suggests matching student skills to roles. However, in our case students skills were relatively unknown until after the simulation. In the future, final country selection will be done earlier to allow students time to develop greater familiarity with their country and there will be more instructor guidance on relevant countries to the simulation topics (using the potential topic list as a guide).

Two of the three groups struggled with topic selection, delaying their research for their policy papers. Feedback indicated that many students were a little overwhelmed by the student directed nature of the subject. As a consequence, in future iterations a set of potential topics for the simulation linked to each of the six committees of the General Assembly, will be provided, though groups will still be given the option of choosing their own topic.

\section{SUBJeCt PROGRESS}

The groups all chose topics related to the current challenges in the Middle East and North Africa, which was interesting as our current curriculum has little on this. Group one represented the First Committee of the GA, Disarmament and International Security Committee (DISEC) and debated foreign fighters in Iraq and Syria. Group two chose the Third Committee, Social, Humanitarian and Cultural Committee, and focused on threats to refugees in UNHCR camps in the Middle East. The final group was also the Third Committee and examined humanitarian intervention in Libya. 
The simulation started with formal opening statements of one minute. Students had to post a brief position statement on the group workspace a few days prior to the class so that others had time to read them. However, there was limited evidence that the statements had been widely read. Classes next generally opted for an unmoderated caucus, which is MUN-speak for informal discussion or suspension of all formal rules of procedure. Next, they moved into a moderated caucus, which dictates that debate must adhere to a specific proposed topic and with constrained speaking times for each delegate. During the first two weeks, the chair explained rules as necessary and made suggestions for directions to ensure the smooth and productive flow of debate. The chair was one of two class instructors present during the simulations. This gave a second instructor time to focus on marking the students' contributions using a rubric that was provided to students. The subject is resource intensive and we are exploring options for future years to reduce this burden, for example having a student as chair. However, this is dependent upon adequate knowledge of MUN rules and procedures, which is not common at Australian universities, particularly those that do not have a history of participation in MUN conferences.

Week two generally started with an unmoderated caucus and in, some groups, working papers (which had been worked on through the week over the online space) were introduced or they were drafted during the class. Students were encouraged to continue discussions between weekly classes through twitter and the group workspace. The efficacy and engagement varied from week-to-week and across the different classes. Online participation counted to the simulation contribution mark, which many students, in particular those who are less confident with public speaking, found useful. Week three saw the working papers drafted into formal resolutions and in week four, the fine points of resolutions were debated before a final vote. All three groups were able to achieve at least one resolution, with one group finalizing two resolutions. For this group, they made a strategic decision to split the two aspects of their resolution, as they would be easier to pass in that way. Although the focus of the subject was on the processes and complexities of international negotiations, we felt that it was important to achieve a resolution to enhance students' sense of achievement and also to feel some closure around the subject. ${ }^{5}$

The resolutions did tend to be a bit generic and include too many platitudes, this is because they were undergraduate students and they picked topics of current international concern but ones they had, in effect, limited factual and conceptual knowledge about. The group discussing the situation in Libya was notably assisted by the open access student who was given the core job of representing the currently recognised Libyan government. This student was mature-aged and was already working in an international relations career in another English-speaking country. This small taste of the potential benefits of the open boundary model was exciting. The broad resolutions led to instructor debate about whether there should be less focus on knowledge on the UN system and more on preparation for the specific simulation topics. However, student feedback in the in-class debriefing indicated they would have liked more on the UN system overall. Further, most diplomats are generalists rather than area experts, thus we consider the current model is more reflective of real world experience than one focused more on area expertise.

The experience on resolution content does, though, highlight the tension in simulation selection between contemporary topics, getting saturated media coverage, which grab students' attention and topics that might not be as "glamorous" but that they have more background in. In 2016, students are being encouraged to focus on the detail of their resolutions. In 2017, we are considering providing students with briefing materials specific to their selected topic, rather than them gathering everything on their own. This will also serve as a leveller between students that may coincidently have more knowledge about the topic than others. However, content overload can stifle engagement and also needs to be avoided. 


\section{Reflections on Key Learning Areas}

In order to evaluate the outcomes of the subject, we gathered a range of qualitative data on student progress in the various levels of knowledge - factual, cognitive, procedural and metacognitive. As noted, assessment tasks were designed around these levels of knowledge, however the key focus was students' reflective journals, which were focused on the conceptual issue of students' learning about theories of IR and, at the metacognitive level, about their perceptions of their professional skills development. These two aspects were key indicators of whether deep learning occurred and were also where we found the most interesting data and, are thus, the focus of this paper.

The analysis of reflective journals was supplemented by other data gathered. Teaching instructors kept notes from observations of the classes and the standard university subject survey collection had some useful data in that section that asks for suggestions and improvements. In addition, during the final debriefing class, notes were kept of outcomes and some students provided anonymous written comments at this session as well. ${ }^{6}$ Ethics approval to use the various data was obtained and we explicitly sought student permission to use their de-identified reflective journals. The data was coded using the learning objectives outlined earlier and we report here outcomes on learning about IR theory and practice and metacognitive growth through assessment of professional skills development. The next sections explore each of these two issues in turn, comparing our findings to similar literature on the topic.

\section{LEARNING IR THEORY THOUgh MODEL UN}

Simulations have been regarded as a useful tool in teaching IR theory. Asal argued that they "can help make complex theory clearer to the student" (Asal 2005, 361). This is because they bring dry material to life through students' own decisions and processes. Students can even experiment with theory through simulations (Asal 2005; Crossley-Frolick 2010; Shellman and Turan 2006; Raymond 2010). In order for simulations to link to IR theory, Asal (2005) notes that the right topic is vital. We found that a MUN is ideal because different parts of the organisation have been influenced by different IR theories. Despite this, Haack $(2008,398)$ found in her analysis of 19 MUN class curriculum a lack of focus on theoretical learning. Indeed, she goes as far as claiming that UN studies overall "is marked by a degree of theoretical poverty." This claim may be a little exaggerated, nevertheless our curriculum aimed to avoid this gap and asked students to reflect upon and challenge societal assumptions and how they influence debate. Students' knowledge of IR theory was refreshed during the module on the UN (it is introduced in first year). They were prompted about it at a number of points during the class and asked specifically to discuss it in their written reflective paper.

In the module on the UN system, links were made between various parts of the UN system and IR theories. For the sake of simplicity we grouped the theories into four: realism, liberalism, social constructivism and critical theories. The open access primer on IR theories developed for the subject provided a range of specific linkages between the UN system and IR theories (Engel and Pallas 2015). For example, the Security Council forms the realist core of the organisation and the General Assembly, with its universal representation and responsibility for promoting economic, social, cultural and other cooperation and for realizing human rights, shows liberalism's influence. For social constructivism, Finnemore's (2003) work on how military interventions shows the evolution of the norms and rules that govern international society was highlighted and, on critical theories, the contribution of neo-Gramscian scholars to studying the influence and power of international financial institutions was discussed. In the evaluations, a number of students commented on the benefits of online lectures and materials in helping them revise, one said:

[t]he online lecture format allowed for greater flexibility and the open access ereadings provided a superior alternative to the classic textbook arrangement, since all of the required readings were actually relevant to the course, and not unnecessarily detailed. ${ }^{7}$ 
Thus the material linked directly and succinctly to IR theories and this was reinforced by the simulation and the requirement that their reflective journal (a key element of the debriefing process) commented on what they learned about IR theories. Student feedback demonstrated the ways in which they came to grips with IR theories. In the 43 journals that we had ethics approval to analyse, 38 of the students referred to theories of IR and, of these, the majority only made links between the more traditional theories of IR, namely realism and liberalism, and the UN system and/or to the roles of particular states. The vast majority of these successfully explained key concepts and issues associated with the two theories, in particular there was much discussion of sovereignty. Many students noted how the connection to the UN made theory more understandable or that it helped them understand the operations of the UN:

IR theory remains daunting, but I have now a (truly) rudimentary grasp, and with this primer as my go-to document, have more confidence in applying the lens of IR theories (emphasis in original).

Understanding these ideas which were presented as course content during the early part of this course proved to be of fundamental importance during simulation, as it assisted in allowing individuals to better understand its own state's position and that of others.

This simulation and entire course also demonstrates the importance of a solid foundation in international relations theory.

During the simulation, I was able to strengthen my knowledge of theories of international relations by identifying them in practice. These theories were represented and at times misrepresented by myself and my classmates...

There was a fairly even balance between those who found realism and those who found liberalism to be most useful in understanding the role and limitations of the UN and the actions of states in it. Quite a few students also highlighted the influence of their own beliefs, explained in terms of IR theories, in either shaping their overall views or in limiting their capacity to represent their chosen country. One student noted how they could better decipher their own assumptions when reading IR analysis and yet another noted how their views had changes as a result of the subject:

My studies in international relations are driven by my liberal belief that international cooperation and a global governing presence are the most viable solutions to the majority of international issues today. My experience in Model United Nations tested both this liberal approach to international relations... The theory and procedural aspects of the subject led me to question several of my assumptions and preconceived ideas of the United Nations and its effectiveness... I thoroughly enjoyed this subject however I finish the semester with a far more realist understanding of current world politics..

While all those who discussed theories used realism and liberalism, only eight of the 43 students mentioned social constructivism and only three mentioned theories that were grouped under the heading of critical theories. This small representation contrasts to the discipline of IR, where social constructivism and "other" paradigms have long taken over from realism and liberalism as the dominant approaches (Morgenbesser 2013, 223-4). Those students discussing social constructivism had, overall, a quite sophisticated approach to theories, effectively demonstrating their deep learning:

We can glean from this that, rather than an enduring narrative that describes the fundamental nature of international relations, the major concepts that define the way international relations 
operate are constantly in flux, and determined by the culture and standards of the day. This reflects the social constructivist approach, which seemed to me the most applicable ultimately.

Social constructivism views ideas and norms as being central to international relations. For instance, in the first committee session, this theory was predominant when ideas of military involvements (in the form of humanitarian aid) were being debated. The whole concept of humanitarian aid is a socially constructed one and therefore could apply to that example.

Only three students discussed any of the critical theories of IR, despite the fact that our program is in fact mostly populated by critical scholars and thus these approaches have a fairly strong presence in the overall curriculum. Of these, one student was taken by neo-Marxism, finding it a "revelation", one student representing a former African colony found inspiration in neo-colonialism and only one noted the relevance of feminism, despite the fact that gender was an issue in two of the simulation topics. A few students also noted the significance of IR theories in understanding why UN reform is so hard:

My experiences in this subject allowed me to relate the international relations theories into real world practice, and see how the theories are evident in global politics... These theories also helped me understand other reasons why the UN's action can be hindered, which is most glaringly obvious through the Security Council and the power of veto.

I walk away from this course with the belief that without a social constructivist upheaval of the current perception of national sovereignty, no international governance will have the capability to implement significant change in the world.

Crossley-Frolick (2010) has concluded that traditional lecture/tutorial formats do not really see students come to grips with the myriad of limits to international organisations due to state sovereignty and the problems of intergovernmental problem solving. We conclude that, despite the overrepresentation of the traditional approaches to IR, the combination of online lectures and resource material and the simulation in our course contributed to students' deep learning about these issues. This is based on not just the number of references to theories but the abstract terms that were used to describe them and the connections made between the theories and the limitations of international organisations and/or the actions of particular states.

\section{Personal Learning in Model UN}

The students were quite frank in their assessments of their own performance in the subject, acknowledging how much effort they had put in and the impact of this on their performance either negatively or positively or when their effort improved. The students' analysis and outcomes needs to be situated in the specific context of simulations being quite foreign to the curriculum, indeed some seven students used the specific term "daunting" to describe their feelings about the simulation and the subject. Nevertheless, all of the students indicated a range of areas where they had learned useful skills. The specific skills identified by multiple students were: communication and public speaking, formal meeting procedures, negotiation, diplomacy, problem solving, research, writing professionally, teamwork and engagement in the digital sphere. Five students indicated that their confidence has increased and we consider that this may be linked to the way that simulations provide experiential learning, which assists in embedding different levels of knowledge (Taylor 2013, 139).

At least ten students felt their public speaking skills had improved, whilst four noted they had not, and often acknowledged that this was due to their own reluctance to engage. The majority just made general statements about their improvement, but this comment shows quite a deep analysis: 
....a major challenge was to speak concisely and powerfully in a way that clearly articulated a concept in a way that was less prone to misinterpretation. ... When attempting to communicate effectively, it was often difficult to deliver statements in a way that was engaging to the audience. This is something that I would like to develop... I have also noticed an absence of the ability to draw conclusions, or to climax an idea or concept.

One interesting aspect raised by four students was their capacity to think on their feet or work under pressure. Three students felt they had improved, while one noted this as an area for improvement. Thinking on your feet and working within a pressured environment is a particularly vital professional skill in IR and indicative of important metacognitive development and one area where simulations do seem to provide greater benefits over traditional teaching methods as students are practicing this skill.

A number of students indicated they had new insights into what their preferred career choice would be sometimes because they confirmed that they were either more suited to policy or research than to public presentations due to their personality traits or that they simply preferred those activities:

...it made me realise that I enjoyed the research and analysis of other country's positions more than being a delegate and the public face representing a country. I did not think this would be the case and has slightly redirected my focus continuing on with my degree.

Others learned how important their values were to them:

I learned how difficult international negotiation can be and realised that were I to work in a representative role in my career, I would work better were I personally aligned with the values and ambitions I represent.

Attempting to faithfully present Costa Rica's position and disregard one's own individual morality proved to be one of the more challenging aspects of the simulation.

Yet another learned that they were able to represent their country rather than their own beliefs with practice and concluded that "the ability to act impersonally will be valuable in further studies and in a professional environment."

On negotiation skills, Crossley-Frolick $(2010,195)$ noted that "...students articulated a greater appreciation for the difficulties involved in international negotiation. Not only did they realize how much actor interests interfere with cooperation, but how different personalities, expectations, and information can impact negotiation processes." We taught negotiation strategies and tactics using an introductory source on integrative (win/win) versus distributive (win/lose) bargaining (CommGAP and World Bank Institute 2010). In addition to many general comments about improved negotiation skills (20 in total), four students provided detailed evaluations of their personal negotiating preferences using this framework. One particularly deep reflection noted:

This was in stark contrast to week 2 of the simulation, where I lacked composure and research and thusly began to unintentionally incorporate distributive forms of negotiation into my plan of attack. It highlights a weakness in me that when under prepared and placed in a pressure situation I slipped into a individually minded logic, and was more focused on achieving my bare minimal individual requirements than upholding a true team mentality.

A number of students commented specifically on the value of the YouTube lecture by Paul Reynolds (2013) "Summit Diplomacy", which demonstrated the benefits of using open access material by relevant experts for teaching. Of course, any simulation has strong limitations when it comes to negotiating skills and one clear one in this case was that the students tended to act cooperatively, even in some cases where the countries they 
represented had quite opposing positions. The students did, however, identify their tendency to be cooperative as an issue and limitation. Many also understood their limitations in terms of representing their country accurately. Overall, the students' reflective journals and other feedback provide quite a wealth of data signalling effective metacognitive learning.

\section{CONCLUSION}

Our approach to Model UN has not fully overcome the challenges to deep learning that Haack $(2008,399)$ identified as partly due to lack of progression specialisation in IR courses and partly due to the lack of theoretical engagement in MUN curriculum, which results in a "tendency to interrogate the subject through questions aimed at a lower cognitive level which further reinforces surface learning." However, by consciously designing our MUN around Anderson and Krathwohl's (2001) four levels of knowledge (factual, conceptual, procedural and metacognitive), building on the insights of existing research into MUN pedagogy and by seriously evaluating the program, we are confident that the subject design encouraged deep learning across all four levels of knowledge. In particular, this evaluation demonstrated deep learning in IR theories and a high level of metacognitive evaluation by students of their professional skills development.

Of course, many challenges remain. For one thing, we are still concerned that the subject is too broad "in a bid to ensure that students achieve an adequate overview of the various aspects of the UN..." (Haack 2008, 401). Some students felt that they did not have enough background on the UN, others focused more on concerns about knowledge of the simulation topics and yet others did not feel prepared for the formal meeting procedures used. Future years will include a little more information on rules and procedures, however, students' comments on their progress over the weeks about procedures indicates that the active learning pedagogy at the core of the subject is effective. The concerns about limited preparation do, to an extent, reflect "real world" experience, where diplomats are generalists and have limited background on many of the issues they need to negotiate. This real world focus in is a strong theme in contemporary tertiary pedagogy debates (Pettenger et al. 2014).

As noted above, some of this trepidation also links to the Australian and local content of very limited engagement with, and knowledge of, MUNs and simulations. The trepidation did likely reduce students' level of enthusiasm for and cooperation with the simulation somewhat and, as Asal $(2005,361)$ has noted, this cooperation is absolutely vital to for a successful simulation. Some students prefer traditional teaching methods and "[r]ole plays may not appeal to all students" (Pettenger et al. 2014, 493). Nevertheless, the number of students who commented that this was an authentic or real world subject gives us the confidence to persist. Further, during and after the MUN a growing number of students participated in a university level, student-run MUN, driving as far as $1,000 \mathrm{~km}$ to attend. Some of our students have gone on to win Diplomacy and Honourable Mention awards at MUN Conferences. We now have an active student society on campus devoted to foreign affairs and diplomacy, and some of our former students took on leadership roles within the society in 2016. Finally, preliminary feedback from the 2016 intake shows that quite a number of students chose the subject precisely because it would challenge them to develop new professional skills.

\section{BIBLIOGRAPHY}

Anderson, Lorin W., and David Krathwohl, R., eds. 2001. A Taxonomy for Learning, Teaching, and Assessing: A Revision of Bloom's Taxonomy of Educational Objectives. New York: Longman.

Asal, Victor. 2005. "Playing Games with International Relations." International Studies Perspective 6 (3):359-73.

Biggs, John, and Catherine Tang. 2011. Teaching for Quality Learning at University: What the Student Does. 4th ed. Maidenhead: Society for Research into Higher Education \& Open University Press. 
Chasek, Pamela S. 2005. "Power Politics, Diplomacy and Role Playing: Simulating the UN Security Council's Response to Terrorism." International Studies Perspective 6 (1):1-19.

CommGAP, and World Bank Institute. 2015. Negotiation 2010 [cited 24 December 2015]. Available from https://www.youtube.com/watch?v=1FeM6kp9Q80.

Crossley-Frolick, Katy A. 2010. "Beyond Model UN: Simulating Multi-Level, Multi-Actor Diplomacy Using the Millemmium Development Goals." International Studies Perspective 11 (2):172-83.

Curtis, Steven. 2012. "How Relevant are Other Ways to Learn?" In Teaching Politics and Internaitonal Relations, ed. C. Gormley-Heenan and S. Lightfoot. Houndsmills, Basingstoke: Palgrave Macmillan.

Engel, Susan. 2016. "Curriculum reform: a transformation or consumption model for politics and international relations?" Australian Journal of Political Science online first:1-13.

Engel, Susan, and Josh Pallas. 2015. International Relations Theory and the UN: A Short Primer 2015 [cited 16 December 2015].

Finnemore, Martha. 2003. The Purpose of Intervention: Changing Beliefs about the Use of Force. Ithaca: Cornell University Press.

Gibson, K., and Carolyn M. Shaw. 2010. "Assessment of Active Learning." In The International Studies Encyclopedia, ed. R. A. Denemark. Oxford: Blackwell Publishing.

Haack, Kirsten. 2008. "UN Studies and the Curriculum as Active Learning Tool." International Studies Perspective 9 (4):359-470.

Hardy, Matthew, and Sally Totman. 2012. "From Dictatorship to Democracy: Simulating the Politics of the Middle East." In About Simulations, Games and Role Play in University Education, ed. C. Nygaard, N. Courtney and E. Leigh. Faringdon, UK: Libri Publishing.

Hatipoglu, Emre, Meltem Müftüler-Baç, and Terri Murphy. 2014. "Simulation Games in Teaching International Relations: Insights from a Multi-Day, Multi-Stage, Multi-Issue Simulation on Cyprus." International Studies Perspective 15 (4):394-406.

Hertel, John P., and Barbara J. Millis. 2002. Using Simulations to Promote Learning in Higher Education: an Introduction. Sterling, VA: Stylus.

Leston-Bandeira, Cristina. 2012. "Enhancing Politics Teaching Through Active Learning." In Teaching Politics and International Relations, ed. C. Gormley-Heenan and S. Lightfoot. Houndsmills, Basingstoke: Palgrave Macmillan.

McIntosh, Daniel. 2001. "The Uses and Limits of the Model United National in an International Relations Classroom." International Studies Perspective 2 (3):269-80.

Morgenbesser, Lee. 2013. "The 2012 TRIP survey of international relations in Australia: one problem to rule us all." Australian Journal of International Affairs 67 (2):218-33.

Petranek, C.F. 2000. "Written Debriefing: The Next Vital Step in Learning with Simulations." Simulations \& Gaming 31 (1):108-19.

Pettenger, Mary, Douglas West, and Niki Young. 2014. "Assessing the Impact of Role Play Simulations on Learning in Canadian and US Classrooms." International Studies Perspective 15 (4):491-508.

Raymond, Chad. 2010. "Do Role-Playing Simulations Generate Measurable and Meaningful Outcomes? A Simulation's Effect on Exam Scores and Teaching Evaluations." International Studies Perspective 11 (1):51-60.

Raymond, Chad, and Simon Usherwood. 2013. "Assessment in Simulations." Journal of Political Science Education 9 (2):157-67.

Reynolds, Paul. 2015. Summit Diplomacy: Some Lessons from History for 21st Century Leaders 2013 [cited 22 December 2015]. Available from https://www.youtube.com/watch?v=RTEFyPhDMtU\&feature=youtu.be.

Shaw, Carolyn M. 2010. "Designing and Using Simulations and Role-Play Exercises." In The International Studies Encyclopedia, ed. R. A. Denemark: Blackwell Publishing.

Shellman, Stephen M., and Kürşad Turan. 2006. "Do Simulations Enhance Student Learning? An Empirical Evaluation of an IR Simulation." Journal of Political Science Education 2 (1):19-32.

Taylor, Kirsten. 2013. "Simulations Inside and Outside the IR Classroom: A Comparative Analysis." International Studies Perspective 14 (2):134-49.

Trueb, Bettina. 2013. "Teaching Students to Write for "Real Life": Policy Paper Writing in the Classroom." PS: Politics Science \& Politics 46 (1):137-41. 


\footnotetext{
${ }^{1}$ The survey, undertaken in 2014-5, was focused on assessing core competencies required in Australian undergraduate politics and international relations curriculum, see (Engel 2016). One notable exception to the dearth of simulations is the Middle East Politics Simulation, an online role play exercise first developed in the early 1990s (Hardy and Totman 2012). One of the new simulations is a MUN run by Deakin University in a diplomacy subject.

${ }^{2}$ For some of their history see (Haack 2008) Haack analysed some 19 randomly selected MUN classes, which also demonstrates their pervasiveness in the US.

${ }^{3}$ On shorter simulations see Asal (2005) and Crossley-Frolick (2010) ; long, complex simulations include: Chasek (2005) and Hatipoglu, Müftüler-Baç and Murphy (2014). For a comparison of the benefits of different types of simulations see Taylor (2013).

${ }^{4}$ The practice session topic was chosen as it is one student's generally have strong opinions on, which increases the engagement and fun for the practice run (McIntosh 2001, 275). The rules were our adaption of MUN rules and are available on the open access website.

${ }^{5}$ Pettenger, West and Young $(2014,497)$ emphasized process in their the simulations but not the importance of a reasoned decision regard the outcomes. In our case, given that the whole subject was structured around the simulation, class instructors helped ensure a resolution was achieved, though we had discussed the possibility of students not achieving a resolution and prepared a debriefing structure for that case.

${ }^{6}$ Quantitative data was also gathered on the usage of the website, twitter feed and group workspace site, which was Wiggo. In the second year of the subject, some innovations in the technology were introduced, which will be evaluated for effectiveness.

${ }^{7}$ A few students did indicate their preference for face-to-face lectures, however, in the later feedback through the subject evaluation, the large majority of comments were positive with regard to the use of online materials and they provided specific feedback on particular expert resources they enjoyed.
} 